\title{
Congenital Granular Cell Tumour: Report of a case with review of literature and differential diagnosis.
}

\author{
arpita singh ${ }^{1}$, Snehashish Ghosh ${ }^{2}$, Anjani Yadav ${ }^{3}$, and Anuja Panthee ${ }^{4}$ \\ ${ }^{1}$ National Medical College and Teaching Hospital \\ ${ }^{2}$ College of Medical Sciences Teaching Hospital \\ ${ }^{3}$ BP Koirala Institute of Health Sciences \\ ${ }^{4}$ KIST Medical College
}

December 29, 2021

\begin{abstract}
Congenital Granular Cell Tumour (CGCT) is a rare benign lesion and presents in newborn as fibrous mass arising from the alveolus. The prenatal screening of lesion can help in parent counselling, determining the complications, as larger size lesion may interfere with normal delivery and require caesarean section.
\end{abstract}

Congenital Granular Cell Tumour: Report of a case with review of literature and differential diagnosis.

\section{Key Clinical Message}

Congenital Granular Cell Tumour (CGCT) is a rare benign lesion and presents in newborn as fibrous mass arising from the alveolus. The prenatal screening of lesion can help in parent counselling, determining the complications, as larger size lesion may interfere with normal delivery and require caesarean section.

Keywords: Fibrous, mass, neumann's Tumour.

\section{Introduction}

Congenital Granular Cell Tumor is a rare benign soft tissue tumor that originates from gingiva of maxillary or mandibular alveolar ridge in newborn. It was first described by Ernst Christian Neumann in 1871 as "Congenital Epulis"1. The other names for CGCT are Neumann's tumor, Congenital Epulis, Congenital Myoblastoma and Gingival Granular Cell Tumor. The term 'epulis' simply means swelling on the gingival thus it was suggested to be discontinued and congenital granular cell tumor to be used in the literature. The incidence of occurrence of the tumor is very low $(0.0006 \%)^{2}$.

The congenital granular cell tumor is seen twice as commonly involving maxillary alveolar ridge to mandibular ridge with incisor canine region being the most prevalent site. The lesion is predominant in females to male. The histogenesis of this tumor is not very clear, several studies have been done but none is conclusive thus various authors have proposed different sources of origin of this tumor. The probable source of origin suggested are from undifferentiated mesenchymal cells ${ }^{4}$, odontogenic epithelial cells, pericytic, fibroblastic, histiocytes, nerve related, smooth muscle and primitive mesenchymal cells. ${ }^{4,5,6}$

We here, report a case of congenital granular cell Tumor (CGCT) in the incisor region of lower alveolar ridge. This case report is unique, owing to the size of the tumour, which is relatively rare, along with it we tried to highlight the differential diagnosis of this particular entity in a separate table which will guide the clinicians to arrive at a correct diagnosis, when they encounter with such a lesion. 


\section{Case report}

One day old newborn was referred to the faculty of dentistry, National Medical College and teaching hospital, Birgunj, Nepal. The child had a normal delivery in the maternity department of the same institution and was referred to us five hours post-delivery for evaluation and management of mass in mouth. On clinical examination the lesion presented with a pedunculated, smooth surfaced mass, which was pink in colour, size about $2.3 \mathrm{~cm} \mathrm{X} 1.8 \mathrm{~cm} \mathrm{X} 1.3 \mathrm{~cm}$ on anterior part of mandibular alveolus. (Figure 1) The tumour mass was relatively large in size, which was interfering with the mouth closure, causing difficulty with the breastfeeding, which was distressing both for the patient and the parent. The provisional diagnosis of Granular Cell tumour was given for the lesion with the differential diagnosis of Embryonal Rhabdomyosarcoma and Melanotic Neuroectodermal Tumour of Infancy. As the lesion was not pulsatile, hemangioma was excluded from the differential diagnosis.

\section{Pre-operative evaluation}

Pediatric consultation was done for the child and routine blood investigations like complete blood count, bleeding time, clotting time, international normalized ratio was done. The reports were found to be within the normal limits. Single dose of 1 milligram vitamin K injection was administered intravenously to prevent vitamin $\mathrm{K}$ deficiency bleeding.

\section{Surgical intervention}

The surgery was performed under intravenous anesthesia Local anesthetic ( $2 \%$ lignocaine) was infiltrated at the base of the lesion to decrease intra-operative bleeding and post-operative pain. The lesion was excised with electrocautery. The excised mass (Figure 2) was fixed in $10 \%$ neutral buffered formalin and sent for histopathological examination.

\section{Histopathologic examination}

\section{Macroscopic examination}

The excised mass was $2.3 \mathrm{~cm} \times 1.8 \mathrm{~cm} \times 1.3 \mathrm{~cm}$ in size, firm in consistency. The cut surface was smooth, without any surface alterations.

\section{Microscopic examination}

The multiple sections of hematoxylin and eosin-stained tissues revealed stratified squamous epithelium lining the lesion showing atrophy of rete ridges and the underlying stroma bears unencapsulated tumor composed of sheets of large, polygonal, round and oval cells with indistinct cell border, granular, eosinophilic cytoplasm and round to oval lightly basophilic nuclei. (Figure 3,4) The microscopic findings were consistent with features of Granular Cell Tumor.

\section{Post-operative evaluation}

The child was observed post-operatively for 3 hours. Feeding was done with the spoon, which she tolerated well. Pediatric review was done and then the child was discharged. The child was never brought to the hospital for the follow up. However, the child's father reported to the department fifteen days post-surgery, stating that the child is doing well.

\section{Discussion}

The clinical course of CGCT is not clear but still it is considered as a benign lesion and does not grow postpartum. It was suggested that trauma due to finger sucking in utero could be a possible cause for the CGCT but it had a little evidence so the concept was discarded. The most recent concept about CGCT is it is either a reactive lesion. Mostly it presents as an isolated lesion but there are reports of it presenting simultaneously with other entities, chiefly neurofibromatosis, transverse facial cleft and blinder syndrome. Rarely it is associated with congenital missing of the tooth germ in the region of its occurrence. As it is a congenital entity, therefore it is associated with prenatal and post-natal complications. ${ }^{4,6}$ 
The clinical diagnosis of CGCT can be made by the presence of fibrous mass in alveolar mucosa of mandible or maxilla at the time of birth. ${ }^{7}$ Clinically the tumor is smooth or lobular surfaced, firm to rubbery in consistency. ${ }^{6,8}$ Typically CGCT occurs as single tumor but case reports with multiple lesions have also been reported involving either one or both jaws. Other abnormalities such as nasal bridges, neurofibroma, polydactyly, Binder syndrome, congenital goiter can be seen with multiple CGCT. ${ }^{4,9,10}$ Although, spontaneous remission has been reported, but still surgical excision remains the treatment of choice for CGCT. $\cdot{ }^{4,9}$ Recurrence or malignant transformation for CGCT has not yet been reported in the litertature. ${ }^{4}$

Prenatal diagnosis of CGCT can be done by ultrasonography as early as 26 weeks of pregnancy. ${ }^{9}$ The commonest prenatal complication associated with CGCT is obstructed deglutition of amniotic fluid, whereas after birth it could be associated with hypoplasia of incisors, midface hypoplasia, feeding difficulties and respiratory obstruction. Hence its diagnosis prenatally is important by ultrasonography, can help in parent counselling regarding the nature and management of disease post-delivery. ${ }^{4,10}$

The size of the lesion may also determine the intervention planning as large lesion may interfere with normal delivery and may require caesarean section. The tumor has no familial tendency; spontaneous regression of the lesion has been reported. However, the best management is surgical excision following which no recurrence or malignant transformation has been reported till date. ${ }^{4,9,10} \mathrm{~A}$ wide range of immunohistochemical (IHC) markers could be used in CGCT including S100, CD 68, CD 105, podoplanin, VEGF. But all cases of CGCT does not show positivity for all these IHC markers speaks for its enigmatic tissue of origin. S100 has been positive in cases of adult granular cell tumour, rather than CGCT, which suggests that CGCT may have a different tissue of origin and the absence of schwann cells. ${ }^{11,12}$

The differential diagnosis for this particular entity includes hemangioma, melanotic neuroectodermal tumour of infancy (MNTI), fibroma embryonal rhabdomyosarcoma, osteosarcoma and chondrosarcoma, malignant granular cell myoblastoma and neurilemmoma. ${ }^{4,13,14}$ The differentiating features are mentioned in table no.1.

\section{Conclusion}

CGCT is a distinctive entity rarely encountered in infants. The exact tissue of origin, course and progression of this entity is obscure which invokes further research. Prenatal diagnosis is important for treatment planning and depending on the size and location of the lesion.

Table No. 1- Differential diagnosis of CGCT along with the differentiating features. ${ }^{13,14,15}$

\begin{tabular}{ll}
\hline Differential Diagnosis & Differentiating Features \\
\hline Hemangioma & It is not present at birth, lined by endothelial cells, and it is pulsatile. \\
MNTI & It is composed of alveolar spaces lined by cuboidal or polygonal cells containing pal \\
Fibroma & It is a benign tumour occurring in adults, composed of collagen fibres in bundles wi \\
Embryonal rhabdomyosarcoma & It is a malignant tumor of striated muscles, containing multiphasic population of ce \\
Osteosarcoma and Chondrosarcoma & They will present with osteoid and chondroid matrices repectively. Moreover presen \\
Malignant granular cell myoblastoma & It usually occurs in middle aged adults. It consists of granular cells in the form of \\
Neurilemmoma & It is typically composed of spindle cells in the form of Antoni A and Antoni B form \\
\hline
\end{tabular}

\section{REFERENCES}

1. E. Neumann. 'Ein fall von kongenitaler epulis,' . Arch Heilkd ; 12.

2. Bosanquet D, Roblin G. Congenital epulis: a case report and estimation of incidence. Int J Otolaryngol 2009; 2009: 508780 .

3. Kim SK, Won HS, Lee SW, Kim JK, Shim JY, Lee PR, Kim A. Prenatal diagnosis of congenital epulis by three-dimensional ultrasound and magnetic resonance imaging. Prenat Diagn . 2006; 26:171-4. 
4. Yuwanati M, Mhaske S, Mhaske A. Congenital granular cell tumor-a rare entity. J Neonatal Surgery . 2015 Apr;4(2).

5. Mirchandani R, Sciubba JJ, Mir R. Granular cell lesions of the jaws and oral cavity: a clinicopathologic, immunohistochemical, and ultrastructural study. J Oral Maxillofac Surg 1989; 47: 1248-55.

6. Fister P, Volavsek M, Novosel Sever M, Jazbec J. A newborn baby with a tumor protruding from the mouth. Diagnosis: congenital gingival granular cell tumor. Acta Dermatovenerol Alp Pannonica Adriat . 2007; 16:128-30.

7. Lack EE, Perez-Atayde AR, McGill TJ, Vawter GF. Gingival granular cell tumor of the newborn (congenital "epulis"): ultrastructural observations relating to histogenesis. Human Pathology.1982;13(7):686-9.

8 Dash JK, Sahoo PK, Das SN. Congenital granular cell lesion \&quot;congenital epulis\&quot;-report of a case. J Indian Soc Pedod Prev Dent 2004; 22: 63-7.

9. Conrad R, Perez MCN. Congenital Granular Cell Epulis. Arch Pathol Lab Med 2014; 138: 128-131.

10. Nakata M, Anno K, Matsumori LT, et al. Prenatal diagnosis of congenital epulis: a case report. Ultrasound Obs Gynecol 2002; 20: 627-629.

11. Bianchi PR, De Araujo VC, Ribeiro JW, Passador-Santos F, Soares de Araujo N, Soares AB. Multiple congenital granular cell epulis: case report and immunohistochemical profile with emphasis on vascularization. Case Rep Dent .2015.

12. Gardner P, Rozzelle A. Congenital Granular Cell Tumor: Case Report and Review. Case Rep Pediatr. 2018 Sep 26;2018.

13. Sivapathasundharam B. Shafer's Textbook of Oral Pathology E-book. Elsevier Health Sciences; 2020 Jul 15.

14. Kumar R, Jaiswal S, Singhal A, Garg R. Congenital granular cell lesion: a rare tumor of new born. $J$ Oral Maxillofac Pathol : 2013 Sep;17(3):440-442.

15. Gan J, Shi C, Liu S, Tian X, Wang X, Ma X, Gao P. Multiple congenital granular cell tumours of the maxilla and mandible: a rare case report and review of the literature. Transl Pediatr2021;10(5):1386-1392. 


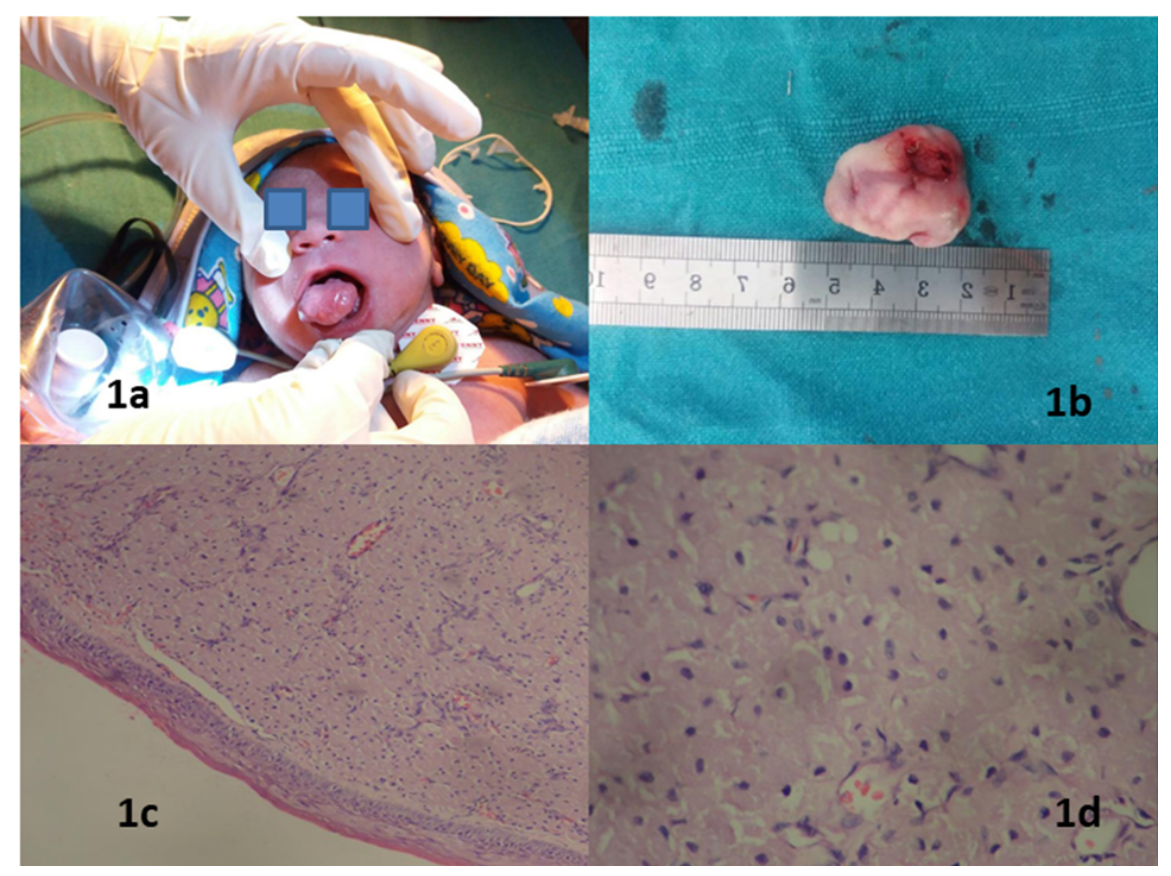

